Subscriber access provided by Caltech Library

\title{
Communication
}

\section{Electrochemical CO reduction builds solvent water into oxygenate products}

\author{
Yanwei Lum, Tao Cheng, William A. Goddard, and Joel W. Ager
}

J. Am. Chem. Soc., Just Accepted Manuscript • DOI: 10.1021/jacs.8b03986 • Publication Date (Web): 16 Jul 2018

Downloaded from http://pubs.acs.org on July 16, 2018

\section{Just Accepted}

"Just Accepted" manuscripts have been peer-reviewed and accepted for publication. They are posted online prior to technical editing, formatting for publication and author proofing. The American Chemical Society provides "Just Accepted" as a service to the research community to expedite the dissemination of scientific material as soon as possible after acceptance. "Just Accepted" manuscripts appear in full in PDF format accompanied by an HTML abstract. "Just Accepted" manuscripts have been fully peer reviewed, but should not be considered the official version of record. They are citable by the Digital Object Identifier (DOI®). "Just Accepted" is an optional service offered to authors. Therefore, the "Just Accepted" Web site may not include all articles that will be published in the journal. After a manuscript is technically edited and formatted, it will be removed from the "Just Accepted" Web site and published as an ASAP article. Note that technical editing may introduce minor changes to the manuscript text and/or graphics which could affect content, and all legal disclaimers and ethical guidelines that apply to the journal pertain. ACS cannot be held responsible for errors or consequences arising from the use of information contained in these "Just Accepted" manuscripts. 


\section{Supporting Information Placeholder}

\begin{abstract}
Numerous studies have examined the electrochemical reduction of $\mathrm{CO}$ (COR) to oxygenates (e.g. ethanol). None considered the possibility that oxygen in the product might arise from water rather than from $\mathrm{CO}$. To test this assumption, $\mathrm{C}^{16} \mathrm{O}$ reduction was performed in $\mathrm{H}_{2}{ }^{18} \mathrm{O}$ electrolyte. Surprisingly, we find that $60-70 \%$ of the ethanol has ${ }^{18} \mathrm{O}$, which must originate from the solvent. We extended our previous all solvent density functional theory metadynamics calculations to consider the possibility of incorporating water, and indeed we find a new mechanism involving a Grotthuss chain of six $\mathrm{H}_{2} \mathrm{Os}$ in a concerted reaction with the ${ }^{*} \mathrm{C}-\mathrm{CH}$ intermediate to form ${ }^{*} \mathrm{CH}-\mathrm{CH}\left({ }^{18} \mathrm{OH}\right)$, subsequently leading to ${ }^{18} \mathrm{O}$ ethanol. This competes with the formation of ethylene that also arises from ${ }^{*} \mathrm{C}-\mathrm{CH}$. These unforeseen results suggest that all previous studies of COR under aqueous conditions must be reexamined.
\end{abstract}

Electrochemical $\mathrm{CO}_{2}$ reduction $\left(\mathrm{CO}_{2} \mathrm{R}\right)$ has emerged as a promising technology to utilize increasingly cheaper renewable electricity to convert $\mathrm{CO}_{2}$ into useful chemicals and fuels. ${ }^{1-6}$ In this context, $\mathrm{Cu}$-based catalysts are currently the most promising for driving $\mathrm{CO}_{2} \mathrm{R}$ to produce significant amounts of multicarbon oxygenates and hydrocarbons such as ethanol and ethylene. ${ }^{7-10}$ Enabling the deterministic design of more selective and efficient catalysts requires understanding of the reaction mechanisms to predict how changes in the catalysts and electrolyte can modify the kinetics and products. Indeed, a number of theoretical papers have been published explaining how the experimentally observed changes in products depend on $\mathrm{pH}$, applied potential, and presence of counter ions. ${ }^{11-14}$ It is generally accepted that on various $\mathrm{Cu}$ surfaces, $\mathrm{CO}_{2}$ reduces first to $\mathrm{CO} .{ }^{15,16}$ At low $\mathrm{pH}, \mathrm{CO}$ can further reduce to ${ }^{*} \mathrm{HCO}$ or $* \mathrm{OCH}$ and then to $* \mathrm{CH}_{2} \mathrm{OH}$, leading to methane or methanol formation. ${ }^{14,17} \mathrm{At} \mathrm{pH}>7$, CO can undergo $\mathrm{C}-\mathrm{C}$ coupling to generate a ${ }^{*} \mathrm{CO}-\mathrm{CO}$ dimer, ${ }^{14,17-21}$ which then forms *OC-COH. ${ }^{22}$ Subsequent steps leading to ethylene and ethanol have been further studied in quantum mechanics (QM) based theory papers. ${ }^{17-19,23-25}$

Recently, we published the first complete determination of the atomistic reaction mechanism for reduction of $\mathrm{CO}$ on $\mathrm{Cu}$ (100) using QM based metadynamics in full solvent to determine the free-energy barriers and kinetics at $298 \mathrm{~K} .{ }^{18} \mathrm{We}$ showed that sol- vent water on the $\mathrm{Cu}$ surface plays an essential role in the mechanisms by providing hydrogen to the intermediates and products. This role of surface water, which involves transferring hydrogen to these intermediates, often through a Grotthuss mechanism involving other solvent waters, was a new result. In our previous QM calculations ${ }^{18}$ for $\mathrm{CO}$ reduction on $\mathrm{Cu}$, we found that the pathway for ethanol formation proceeds through $*(\mathrm{OH}) \mathrm{C}-\mathrm{CH}$; an intermediate after $4 e^{-}$transfers, which then subsequently either reduces to ${ }^{*} \mathrm{C}-\mathrm{CH}$ (leading to ethylene formation with a free energy barrier of $0.61 \mathrm{eV}$ ) or to ${ }^{*} \mathrm{H}(\mathrm{OH}) \mathrm{C}-\mathrm{CH}$ (leading to ethanol with a free energy barrier of $0.67 \mathrm{eV}$ ). However, we did not consider the possibility that solvent water could provide the $\mathrm{O}$ in the products, and we assumed that all the $\mathrm{O}$ atoms in the oxygenate $\left(\mathrm{C}_{\mathrm{n}} \mathrm{H}_{\mathrm{m}} \mathrm{O}_{\mathrm{x}}\right)$ products come from the original $\mathrm{CO}$ molecule being reduced. In fact, this is a common feature of all current proposed mechanisms, with recent work from Head-Gordon and co-workers predicting that none of the oxygenate products should possess oxygen from the solvent water. ${ }^{23}$

We tested this critical assumption experimentally by carrying out reduction of $\mathrm{C}^{16} \mathrm{O}$ in $\mathrm{H}_{2}{ }^{18} \mathrm{O}$ electrolyte on various $\mathrm{Cu}$ surfaces and quantifying the isotopic composition of the products using gas chromatography-mass spectrometry (see SI for more details). An important reason that $\mathrm{CO}$ reduction and not $\mathrm{CO}_{2}$ reduction was performed is because $\mathrm{CO}_{2}$ is known to rapidly equilibrate with water to form bicarbonate. ${ }^{26}$ Therefore, dissolved $\mathrm{CO}_{2}$ would likely incorporate ${ }^{18} \mathrm{O}$ from the solvent, resulting in ${ }^{18} \mathrm{O}$ in the products. In contrast, $\mathrm{CO}$ does not exchange $\mathrm{O}$ with water (see SI for more details). The reduction of $\mathrm{C}^{16} \mathrm{O}$ in $0.05 \mathrm{M} \mathrm{K}_{2} \mathrm{CO}_{3}(\mathrm{pH}$ 11.3) electrolyte was carried out with different $\mathrm{Cu}$ orientations: $\mathrm{Cu}$ (111), $\mathrm{Cu}(100)$ and $\mathrm{Cu}$ (751) at a potential of $-0.64 \mathrm{~V}$ vs RHE. Analysis of the isotopic composition of the products (Figure 1a) reveals that the majority of the ethanol, acetate and 1-propanol are ${ }^{18} \mathrm{O}$ enriched. In order to ensure that incorporation of ${ }^{18} \mathrm{O}$ into the products were not solely due to homogenous reactions occurring in the bulk of the electrolyte (e.g. Cannizzaro reactions ${ }^{27}$ ), a series of control experiments were conducted (see SI for more details). Control experiments were also performed to ensure that the mass spectrometer has similar detection sensitivities for ${ }^{16} \mathrm{O}$ vs ${ }^{18} \mathrm{O}$ fragments (see SI for more details).

For all three $\mathrm{Cu}$ surfaces, the fraction of ethanol with ${ }^{18} \mathrm{O}$ is around $66 \%$ and that for 1-propanol is around $72 \%$. Acetate possesses 2 oxygen atoms and therefore may have 3 different config- 
urations: ${ }^{16} \mathrm{O}^{16} \mathrm{O},{ }^{16} \mathrm{O}^{18} \mathrm{O}$ and ${ }^{18} \mathrm{O}^{18} \mathrm{O}$ acetate. ${ }^{18} \mathrm{O}^{18} \mathrm{O}$ acetate was not observed on any of the $\mathrm{Cu}$ surfaces and the distribution of ${ }^{16} \mathrm{O}^{16} \mathrm{O}$ versus ${ }^{16} \mathrm{O}^{18} \mathrm{O}$ depends on the $\mathrm{Cu}$ orientation, with $\mathrm{Cu}$ (100) producing the highest fraction of ${ }^{16} \mathrm{O}^{18} \mathrm{O}(>90 \%)$. Additionally, allyl alcohol (prop-2-en-1-ol) was detected as a product on all surfaces and methanol only on the $\mathrm{Cu}(111)$ surface. Interest-
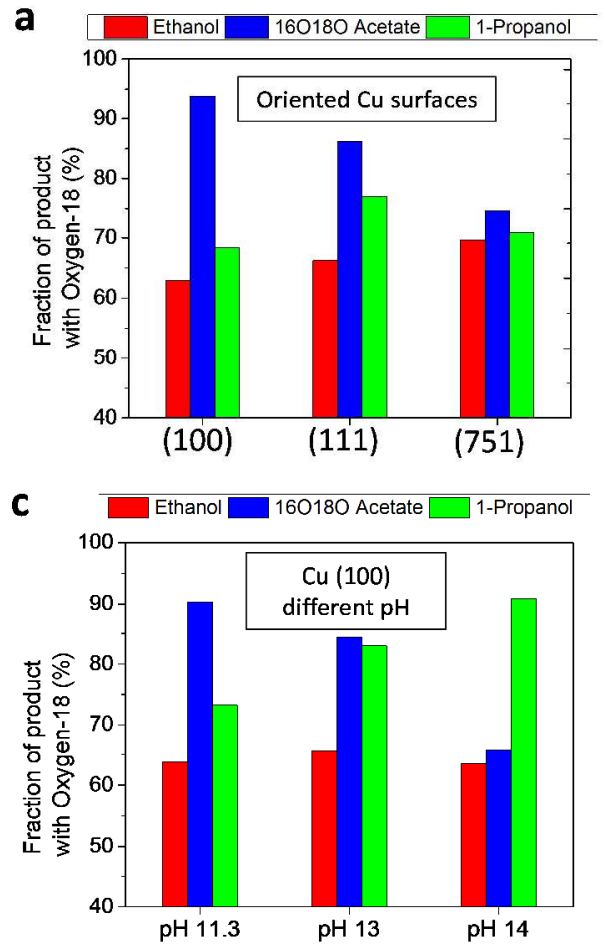

ingly, allyl alcohol and methanol were not enriched with ${ }^{18} \mathrm{O}$, which suggests that the mechanisms for their formation may be very different. These findings are summarized in a chart in Figure $1 \mathrm{~b}$, which sorts the products into those with ${ }^{18} \mathrm{O}$ and those without ${ }^{18} \mathrm{O}$.

b

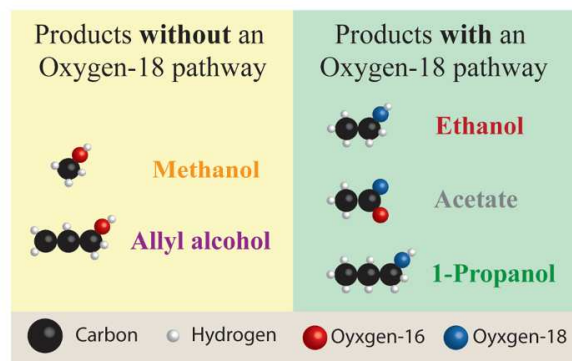

d

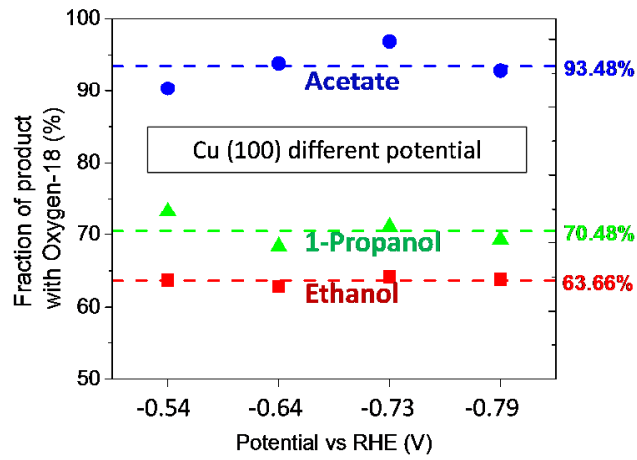

Figure 1. Fraction of product with ${ }^{18} \mathrm{O}$ for ethanol (red), acetate (yellow) and 1-propanol (green) for $\mathrm{C}^{16} \mathrm{O}$ reduction in $\mathrm{H}_{2}{ }^{18} \mathrm{O}$ electrolyte with: (a) different $\mathrm{Cu}$ orientations tested at c.a. $-0.65 \mathrm{~V}$ vs RHE, (c) $\mathrm{Cu}(100)$ at different $\mathrm{pH}$ and (d) $\mathrm{Cu}(100)$ at different applied potentials. (b): A chart showing products with an ${ }^{18} \mathrm{O}$ pathway (ethanol, acetate and 1-propanol) and products without an ${ }^{18} \mathrm{O}$ pathway (methanol and allyl alcohol). Note: ${ }^{18} \mathrm{O}^{18} \mathrm{O}$ acetate was never observed as a product. Faradaic efficiency data are available in the SI.

Next, the effect of $\mathrm{pH}$ and potential was investigated for the $\mathrm{Cu}$ (100) surface. A potential of around $-0.53 \mathrm{~V}$ vs RHE was applied at different $\mathrm{pH} ; 11.3\left(0.05 \mathrm{M} \mathrm{K}_{2} \mathrm{CO}_{3}\right), 13(0.1 \mathrm{M} \mathrm{KOH})$ and 14 $(1.0 \mathrm{M} \mathrm{KOH})$. Figure $1 \mathrm{c}$ shows that changing the $\mathrm{pH}$ has no effect on the ${ }^{18} \mathrm{O}$ composition of ethanol, which remains at around $64 \%$. On the other hand, the ${ }^{18} \mathrm{O}$ composition of acetate and 1propanol are significantly affected by $\mathrm{pH}$. For 1-propanol, the ${ }^{18} \mathrm{O}$ composition rises from $73 \%$ at $\mathrm{pH} 11.3$ to $91 \%$ at $\mathrm{pH} 14$. However, for acetate, the ${ }^{16} \mathrm{O}^{18} \mathrm{O}$ composition decreases from $90 \%$ at $\mathrm{pH}$ 11.3 to $66 \%$ at $\mathrm{pH} 14$. Keeping the $\mathrm{pH}$ constant at 11.3 and changing the potential (Figure 1d) has no effect on the isotopic composition of the products. Additionally, changing the potential or $\mathrm{pH}$ does not result in any ${ }^{18} \mathrm{O}^{18} \mathrm{O}$ acetate formation.

Summarizing the experiments, by using ${ }^{18} \mathrm{O}$ labeling of the solvent we have discovered that that the majority of the ethanol, acetate and 1-propanol produced by $\mathrm{COR}$ on single crystal $\mathrm{Cu}$ surfaces possess ${ }^{18} \mathrm{O}$, showing conclusively that solvent water plays a dominant role in their formation. As a result of this unexpected finding, all previous mechanisms for the formation of $\mathrm{C}_{\mathrm{n}} \mathrm{H}_{\mathrm{m}} \mathrm{O}_{\mathrm{x}}$ oxygenates require reexamination because $\mathrm{H}_{2} \mathrm{O}$ as the dominant source of $\mathrm{O}$ for the formation of these products has been overlooked.

Stimulated by the experimental results, we used quantum mechanics (QM) metadynamics in with full solvent (5 layers) to determine the free energy barriers at $298 \mathrm{~K}$ to investigate how
$\mathrm{H}_{2}{ }^{18} \mathrm{O}$ (solvent) could contribute ${ }^{18} \mathrm{O}$ to the product. The experimental results clearly demonstrate the existence of two ethanol formation pathways $\left({ }^{16} \mathrm{O}\right.$ pathway and ${ }^{18} \mathrm{O}$ pathway). Therefore, the $\mathrm{H}_{2}{ }^{18} \mathrm{O}$ must react with a $\mathrm{C}_{2}$ intermediate which has lost both its oxygen atoms: either ${ }^{*} \mathrm{C}-\mathrm{CH},{ }^{*} \mathrm{C}-\mathrm{CH}_{2}$ or ${ }^{*} \mathrm{HC}-\mathrm{CH}_{2}$. We considered that the most plausible $\mathrm{C}_{2}$ intermediate to react with ${ }^{18} \mathrm{O}$ water is adsorbed ethynyl $\left({ }^{*} \mathrm{C}-\mathrm{CH}\right)$.

Thus, we explored the possibility of a two-step ${ }^{*} \mathrm{CH}-\mathrm{CH}\left({ }^{18} \mathrm{OH}\right)$ formation:

1. First, one surface $\mathrm{H}_{2}{ }^{18} \mathrm{O}$ might provide a proton $\left(\mathrm{H}^{+}\right)$to form ${ }^{*} \mathrm{HC}-\mathrm{CH}$ plus surface ${ }^{18} \mathrm{OH}\left({ }^{* 18} \mathrm{OH}\right)$ via proton-coupled electron transfer (PCET).

2. Second, this might be followed by ${ }^{* 18} \mathrm{OH}$ extracting an $\mathrm{H}^{+}$ from a solvent $\mathrm{H}_{2}{ }^{18} \mathrm{O}$ to deliver the ${ }^{18} \mathrm{OH}$ to form ${ }^{*} \mathrm{CH}$ $\mathrm{CH}\left({ }^{18} \mathrm{OH}\right)$ via PCET.

However, the free energy barrier for the first step is $1.09 \mathrm{eV}$ while the that for the $2 \mathrm{nd}$ step is $1.22 \mathrm{eV}$. These barriers are much larger than the values of 0.61 and $0.67 \mathrm{eV}$ that we found previously to produce ethene and ethanol. Thus we conclude that this mechanism does not explain the large amount of ${ }^{18} \mathrm{O}$ ethanol observed.

We then investigated a concerted pathway of water addition reaction via Grotthuss water chain in which the water at $\mathrm{C}$ end provide $\mathrm{H}^{+}$to $\mathrm{C}$ (in ${ }^{*} \mathrm{C}-\mathrm{CH}$ ) while water at $\mathrm{CH}$ end simultaneously providing ${ }^{18} \mathrm{OH}^{-}$to $\mathrm{CH}$ (in ${ }^{*} \mathrm{C}-\mathrm{CH}$ ) which are connected by the 
hydrogen bond network through bridging water molecules. We considered several possible such chains with the best involves 6 water molecules, leading to a free energy reaction barrier for this reaction of $0.81 \mathrm{eV}$. We also examined this reaction for chemisorbed ethyne $\left({ }^{*} \mathrm{HC}-\mathrm{CH}\right)$ to form ${ }^{*} \mathrm{CH}_{2}-\mathrm{CH}\left({ }^{18} \mathrm{OH}\right)$ and we find a slightly higher barrier of $0.84 \mathrm{eV}$. Finally, we also examined the reaction where ${ }^{*} \mathrm{C}-\mathrm{CH}$ (ethynyl) forms $*{ }^{*} \mathrm{C}\left({ }^{18} \mathrm{OH}\right) \mathrm{H}-\mathrm{CH}$, where we find a barrier of $0.91 \mathrm{eV}$. Thus, we distinguish the formation of ${ }^{*} \mathrm{CH}-\mathrm{CH}\left({ }^{18} \mathrm{OH}\right)$ from ${ }^{*} \mathrm{C}-\mathrm{CH}$ via water addition as the most possible mechanism attributes to $\mathrm{C}_{2} \mathrm{H}_{5}\left({ }^{18} \mathrm{OH}\right)$ formation, which we refer as Grotthuss Chain Ethynyl Concerted Hydrolysis (GECH), a most unexpected and unprecedented reaction which has never been reported before. The critical steps of such unprecedented non-electrochemical reaction from QM metadynamics snapshots are as shown in Figure 2 (see also supplementary movie 1)."

After the formation of ${ }^{*} \mathrm{CH}-\mathrm{CH}\left({ }^{18} \mathrm{OH}\right)$ from ${ }^{*} \mathrm{C}-\mathrm{CH}$ via water addition, the remaining steps toward $\mathrm{C}_{2} \mathrm{H}_{5}\left({ }^{18} \mathrm{OH}\right)$ formation and the related energetics are as shown in Figure 3. GECH is expected to be independent of $\mathrm{pH}$ and applied potential. In the SI, we report a simulation with explicit consideration of $1 \mathrm{M} \mathrm{NaOH}$ $(\mathrm{pH}=14)$ where we found the free energy barrier of $0.87 \mathrm{eV}$, supporting this claim. The experimental results in Figures 1c and $\mathrm{d}$ do not show a large dependence on either $\mathrm{pH}$ or potential, supporting our claim the GECH is responsible for the formation of ${ }^{18} \mathrm{O}$

ethanol.

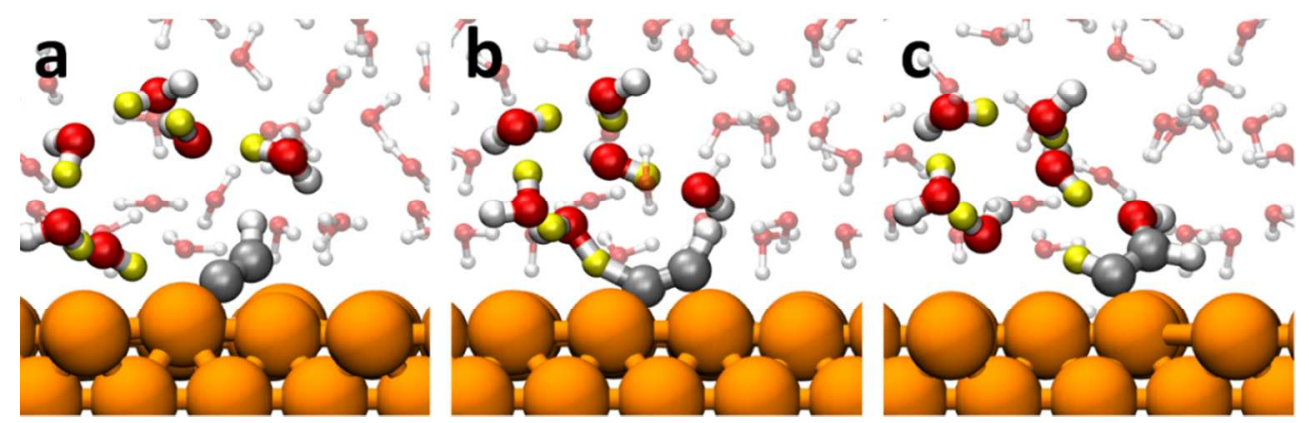

Figure 2. The reactive trajectory for Grotthuss Chain Ethynyl Concerted Hydrolysis $(\mathrm{GECH})$ the of $* \mathrm{C}-\mathrm{CH}$ to ${ }^{*} \mathrm{CH}-\mathrm{CH}(\mathrm{OH})$ from full solvent quantum mechanics molecular metadynamics free energy calculations. All the 6 waters in the Grotthuss chain are shown in full. The other $\mathbf{4 8}$ water molecules not involved in the chain are faded out for clarity. This intermediate $\mathrm{CH}-\mathrm{CH}(\mathrm{OH}) \mathrm{subsequently} \mathrm{forms} \mathrm{etha-}$ nol as shown in the orange pathway in Figure 3. We examined a number of possible pathways involving various numbers of waters, with this being the most favorable. (a) initial reactants, (b) transition state (free energy barrier: $0.81 \mathrm{eV}$ ) and (c) final products (exothermic by $0.12 \mathrm{eV}$ ). The colors are $\mathrm{C}$ in gray, $\mathrm{O}$ in red, the $\mathrm{H}$ involved in the Grotthuss chain proton transfer) are in yellow, and other $\mathrm{H}$ are white.

Since $*\left({ }^{16} \mathrm{OH}\right) \mathrm{C}-\mathrm{CH}$ is a common intermediate for forming either ${ }^{16} \mathrm{O}$ ethanol or to the sum of ethylene and ${ }^{18} \mathrm{O}$ ethanol (see Figure 3), the predicted energy barriers at $298 \mathrm{~K}(0.67$ and 0.61 $\mathrm{eV}$ respectively) can be used to estimate the ratio of the sum of ethylene plus ${ }^{18} \mathrm{O}$ ethanol product to ${ }^{16} \mathrm{O}$ ethanol. Based on the Arrhenius equation, this ratio was calculated to be 11 which is in excellent agreement with our experiments, which yield a ratio of 14 and a calculated energy difference in barriers of $0.066 \mathrm{eV}$ (see Figure S28 for calculation details). Similarly, ${ }^{*} \mathrm{C}-\mathrm{CH}$ is a common intermediate for forming both ${ }^{18} \mathrm{O}$ ethanol and ethylene and the predicted activation energies at $298 \mathrm{~K}(0.81$ and $0.61 \mathrm{eV})$ can be compared to the observed ratio of 0.15 , which implies that the difference in barriers is $0.049 \mathrm{eV}$. This difference in experiment and theory suggests that we may not have exhausted on all the pathways for the GECH mechanism.

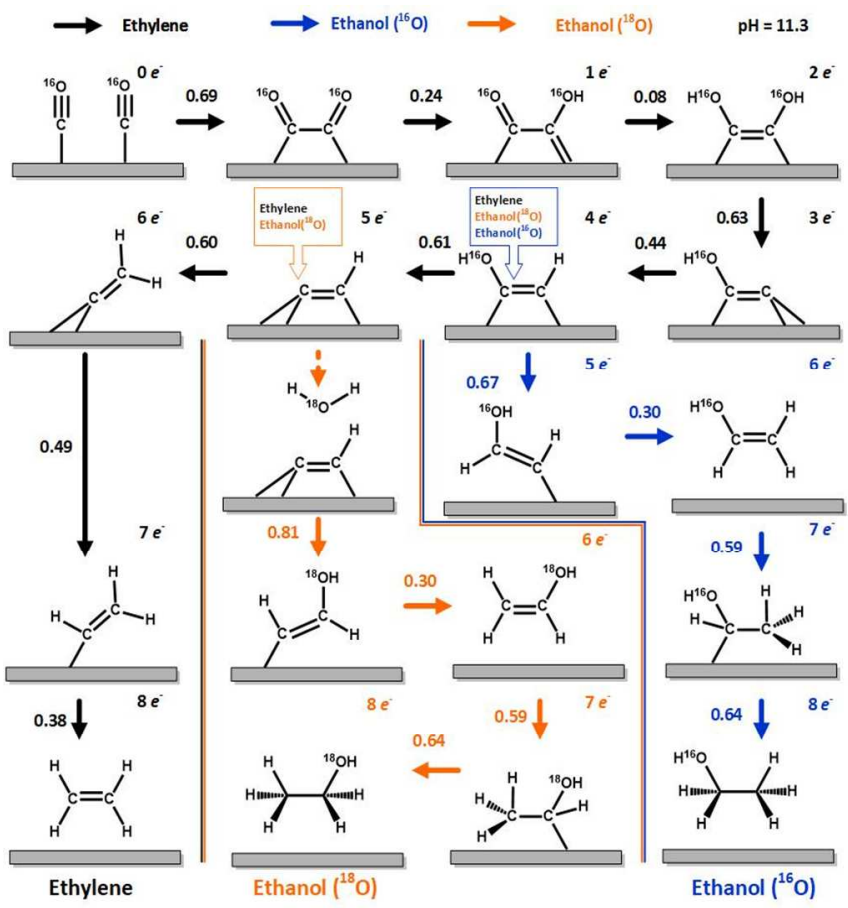

Figure 3. The mechanistic pathways for $\mathrm{CO}$ reduction predicted from full solvent quantum mechanics based molecular metadynamics to obtain free energy reaction barriers at $298 \mathrm{~K}$. The pathways of ethylene formation (black) and ${ }^{16} \mathrm{O}$ ethanol (blue) are from ref 18 . The ${ }^{18} \mathrm{O}$ ethanol formation pathway (orange) is a newly discovered mechanism $(\mathrm{GECH})$ reported here. 
In summary, our QM based metadynamics show that ${ }^{18} \mathrm{O}$ ethanol results from a solvent based concerted hydrolysis of ${ }^{*} \mathrm{C}-\mathrm{CH}$ (chemisorbed ethyne) to ${ }^{*} \mathrm{CH}-\mathrm{CH}(\mathrm{OH})$, in which the added $\mathrm{H}$ and $\mathrm{OH}$ are derived from waters at the opposite ends of a 6 molecule Grotthuss chain $(\mathrm{GECH})$. This is a brand-new mechanism, which is independent of $\mathrm{pH}$ and applied potential and may provide new approaches to designing nanoscale structures and compositions in which the energy and orientation of the chemisorbed ethynyl intermediates are used to promote the solvent water induced ethanol or other $\mathrm{C}_{\mathrm{n}} \mathrm{H}_{\mathrm{m}} \mathrm{O}_{\mathrm{x}}$ oxygenate products.

In this work, the main focus was to understand the formation of ${ }^{18} \mathrm{O}$ ethanol was because it is the most abundant ${ }^{18} \mathrm{O}$ oxygenate produced. Subsequent work will examine the $\mathrm{C}_{3}$ product pathways for 1-propanol and allyl alcohol formation as well as the acetate pathways, which are evidently more complicated. Since we now know that incorporation of ${ }^{18} \mathrm{O}$ is critical in the formation of oxygenates, it is paramount to use this technique to investigate other catalyst systems used for COR such as bimetallic systems and oxide-derived $\mathrm{Cu}^{28-32}$ For example, oxide-derived $\mathrm{Cu}$ catalysts have been shown to yield a high selectivity towards oxygenates versus hydrocarbons. ${ }^{31}$ It is expected that such experiments will lead to new insights on how oxygenate formation mechanisms might be different on these catalysts. Finally, our discovery of concerted solvent water incorporation of $\mathrm{O}$ into oxygenates may have implications for many other oxygen insertion processes.

\section{ASSOCIATED CONTENT}

\section{Supporting Information}

The Supporting Information is available free of charge on the ACS Publications website. Synthesis, characterization, experimental methods and control experiments.

\section{AUTHOR INFORMATION}

\section{Corresponding Author}

*wag@,wag.caltech.edu

*jwager@lbl.gov

\section{Author Contributions}

${ }^{\perp}$ These authors contributed equally.

\section{Notes}

The authors declare no competing financial interests.

\section{ACKNOWLEDGMENT}

This material is based upon work performed by the Joint Center for Artificial Photosynthesis, a DOE Energy Innovation Hub, supported through the Office of Science of the U.S. Department of Energy under Award Number DE-SC0004993. Y.L. acknowledges the support of an A*STAR National Science Scholarship. The quantum mechanics (QM) calculations used the resources of the Extreme Science and Engineering Discovery Environment (XSEDE) which is supported by National Science Foundation grant number ACI-1053575. We thank Lingfei Wei for technical illustrations.

\section{REFERENCES}

Hori, Y. In Modern Aspects of Electrochemistry; Vayenas, C. G., White, R. E., Gamboa-Aldeco, M. E., Eds.; Modern Aspects of Electrochemistry; Springer New York: New York, NY, 2008; pp 89-189.

(2) Montoya, J. H.; Seitz, L. C.; Chakthranont, P.; Vojvodic, A.; Jaramillo, T. F.; Nørskov, J. K. Nat. Mater. 2016, 16, 70-81.

(3) Qiao, J.; Liu, Y.; Hong, F.; Zhang, J. Chem. Soc. Rev. 2014, 43, 631-675.

(4) Chu, S.; Cui, Y.; Liu, N. Nat. Mater. 2016, 16, 16-22.

(5) Graves, C.; Ebbesen, S. D.; Mogensen, M.; Lackner, K. S. Renew. Sustain. Energy Rev. 2011, 15, 1-23.

(6) Singh, M. R.; Clark, E. L.; Bell, A. T. Proc. Natl. Acad. Sci. 2015, 112, E6111-E6118.

(7) Hori, Y.; Murata, A.; Takahashi, R. J. Chem. Soc. Faraday Trans. 1 Phys. Chem. Condens. Phases 1989, 85, 2309.

(8) Kuhl, K. P.; Cave, E. R.; Abram, D. N.; Jaramillo, T. F. Energy Environ. Sci. 2012, 5, 7050-7059.

(9) Kuhl, K. P.; Hatsukade, T.; Cave, E. R.; Abram, D. N.; Kibsgaard, J.; Jaramillo, T. F. J. Am. Chem. Soc. 2014, 136, 14107-14113.

(10) Kim, D.; Kley, C. S.; Li, Y.; Yang, P. Proc. Natl. Acad. Sci. 2017, 114, 10560-10565.

(11) Pérez-Gallent, E.; Marcandalli, G.; Figueiredo, M. C.; CalleVallejo, F.; Koper, M. T. M. J. Am. Chem. Soc. 2017, 139, 16412-16419.

(12) Resasco, J.; Chen, L. D.; Clark, E.; Tsai, C.; Hahn, C.; Jaramillo, T. F.; Chan, K.; Bell, A. T. J. Am. Chem. Soc. 2017, 139.

(13) Resasco, J.; Lum, Y.; Clark, E.; Zeledon, J. Z.; Bell, A. T. ChemElectroChem 2018, 5, 1064-1072.

(14) Xiao, H.; Cheng, T.; Goddard, W. A.; Sundararaman, R. J. Am Chem. Soc. 2016, 138, 483-486.

(15) Hori, Y.; Takahashi, R.; Yoshinami, Y.; Murata, A. J. Phys. Chem. B 1997, 101, 7075-7081.

(16) Peterson, A. A.; Abild-Pedersen, F.; Studt, F.; Rossmeisl, J.; Nørskov, J. K.; Norskov, J. K. Energy Environ. Sci. 2010, 3, 1311-1315.

(17) Xiao, H.; Cheng, T.; Goddard, W. A. J. Am. Chem. Soc. 2017 $139,130-136$

(18) Cheng, T.; Xiao, H.; Goddard, W. A. Proc. Natl. Acad. Sci. 2017, 114, 1795-1800.

(19) Calle-Vallejo, F.; Koper, M. T. M. Angew. Chemie Int. Ed. 2013, 52, 7282-7285.

(20) Sandberg, R. B.; Montoya, J. H.; Chan, K.; Nørskov, J. K. Surf. Sci. 2016, 654, 56-62.

(21) Goodpaster, J. D.; Bell, A. T.; Head-Gordon, M. J. Phys. Chem. Lett. 2016, 1471-1477.

(22) Pérez-Gallent, E.; Figueiredo, M. C.; Calle-Vallejo, F.; Koper, M. T. M. Angew. Chemie Int. Ed. 2017, 56, 3621-3624.

(23) Garza, A. J.; Bell, A. T.; Head-Gordon, M. ACS Catal. 2018, 8, 1490-1499.

(24) Luo, W.; Nie, X.; Janik, M. J.; Asthagiri, A. ACS Catal. 2016, 6, 219-229.

(25) Nie, X.; Esopi, M. R.; Janik, M. J.; Asthagiri, A. Angew. Chemie Int. Ed. 2013, 52, 2459-2462.

(26) Wang, X.; Conway, W.; Burns, R.; McCann, N.; Maeder, M. J. Phys. Chem. A 2010, 114, 1734-1740.

(27) Birdja, Y. Y.; Koper, M. T. M. J. Am. Chem. Soc. 2017, 139, 2030-2034.

(28) Ma, S.; Sadakiyo, M.; Heima, M.; Luo, R.; Haasch, R. T.; Gold, J. I.; Yamauchi, M.; Kenis, P. J. A. J. Am. Chem. Soc. 2017, $139,47-50$

(29) Ren, D.; Ang, B. S.-H.; Yeo, B. S. ACS Catal. 2016, 6, 8239 8247.

(30) Kim, D.; Resasco, J.; Yu, Y.; Asiri, A. M.; Yang, P. Nat. Commun. 2014, 5, 4948.

(31) Li, C. W.; Ciston, J.; Kanan, M. W. Nature 2014, 508, 504-507.

(32) Roberts, F. S.; Kuhl, K. P.; Nilsson, A. Angew. Chemie 2015, $127,5268-5271$. 


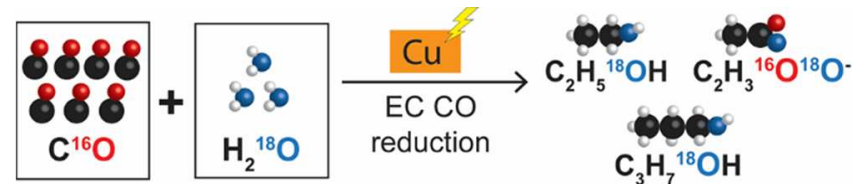




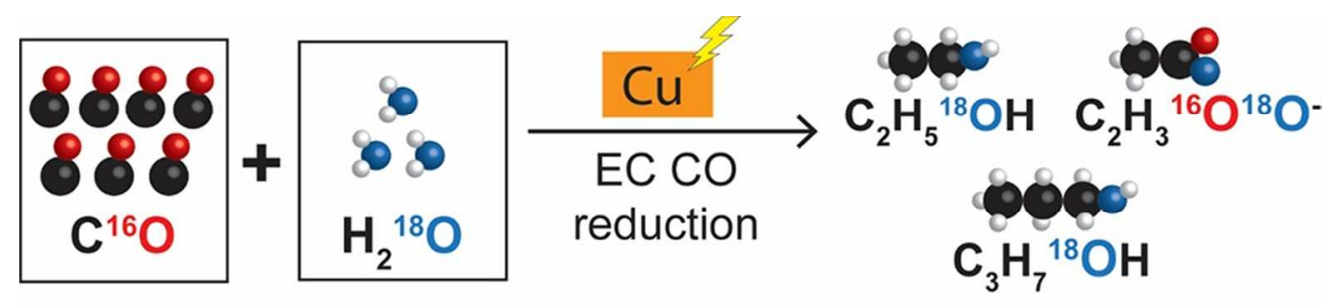

TOC graphic, correctly sized

$85 \times 19 \mathrm{~mm}$ (300 x 300 DPI) 